DOI 10.22460/jpmi.v1i3.219-228

\title{
MENINGKATKAN KEMAMPUAN BERPIKIR KREATIF MAHASISWA MATEMATIK MELALUI PENDEKATAN PROBLEM POSING BERBANTUAN VISUAL BASIC APPLICATION FOR EXCEL
}

\author{
Martin Bernard \\ IKIP Siliwangi, J1. Terusan Jenderal Sudirman, Cimahi, Jawa Barat, Indonesia \\ Pamartin23rnard@gmail.com
}

\begin{abstract}
Today's mathematics courses are a much-feared lesson learned by many of the students from elementary to senior levels. This encourages every student as a potential teacher should have the ability to come up with new ideas to overcome the difficulties of students to learn math. One of them is the student must create learning media using props. Surely the props are made will take no time. Therefore, ICT is the most effective medium to create visual aids and make learning mathematics students become active and fun. The program used by students is Microsoft Excel by using Visual Basic Application language program. The program helps students create creative math skills to create new math learning media based on statements from various objects formed into a medium. learning is done by using a problem posing approach where from one statement as a matter of the object images are available will be arranged in the computer, the tasks of students create different ways that are run with Visual Basic Application for Excel. The students' creative ratings can be seen during the initial task of creating his work and the end of his creation and will show how much better the student creative changes while using Visual Basic for Excel, and the assessment uses the t test in the two classes to see the average difference of the two classes ie mathematics learning using ICT that uses the approach of problem posing and the usual way. Keywords: mathematical connection, material wake flat, qualitative descriptive
\end{abstract}

\begin{abstract}
Abstrak
Mata pelajaran matematika saat ini merupakan pelajaran yang masuh ditakuti oleh banyak siswa-siswa dari tingkat dasar sampai tingkat menengah atas. Hal ini mendorong setiap mahasiswa sebagai calon guru harus memiliki kemampuan untuk memunculkan ide baru untuk mengatasi kesulitan siswa-siswa untuk belajar matematika. Salah satunya adalah mahasiswa harus menciptakan media pembelajaran menggunakan alat peraga. Tentunya alat peraga yang dibuat akan membutuhkan waktu yang tidak sebentar. Oleh sebab itu, TIK merupakan suatu media yang paling efektif untuk menciptakan alat peraga yang berupa visual dan menjadikan belajar matematika siswa menjadi aktif dan menyenangkan. Program yang digunakan oleh mahasiswa adalah Microsoft Excel dengan menggunakan bahasa program Visual Basic Application. Program tersebut membantu mahasiswa-mahasiswa menciptakan kemampuan kreatif matematika untuk membuat media pembelajaran matematika yang baru berdasarkan pernyataan dari berbagai obyek yang dibentuk menjadi sebuah media. pembelajaran yang dilakukan dengan menggunakan pendekatan problem posing dimana dari satu pernyataan sebagai masalah yaitu gambaran-obyek obyek yang tersedia akan disusun dalam komputer, tugas mahasiswa-mahasiswa membuat cara yang berbeda yang dijalankan dengan Visual Basic Application for Excel. Penilaian kreatif mahasiswa-mahasiswa dapat dilihat saat tugas awal pembuatan karyanya dan akhir pembuatannya dan akan terlihat seberapa besar perubahan kreatif mahasiswa yang lebih baik saat menggunakan Visual Basic for Excel, dan penilaian tersebut menggunakan uji $t$ pada dua kelas untuk
\end{abstract}


melihat perbedaan rata-rata dua kelas yaitu pembelajaran matematika yang menggunakan TIK yang menggunakan pendekatan problem posing dan cara biasa.

Kata Kunci: Kemampuan Berpikir Kreatif, Pendekatan Problem Posing, Visual Basic Application for Excel

How to cite: Bernard, M. (2018). Meningkatkan Kemampuan Berpikir Kreatif Mahasiswa Matematik melalui Pendekatan Problem Posing Berbantuan Visual Basic Application For Excel, 1 (1), 69-78.

\section{PENDAHULUAN}

Media pembelajaran matematika merupakan salah satu alat bantu untuk menyampaikan materimateri matematika ke dalam bentuk nyata dengan tujuannya siswa dapat memahami penggunaan matematika tidak hanya sekedar menghafal. Strategi pembelajaran yang perlu dilakukan oleh calon guru atau mahasiswa harus mengetahui permasalahan yang ada di lapangan saat-saat siswa mengalami kesulitan belajar matematika. kendala siswa saat belajar matematika karena kesulitan memahami proses berpikir matematika penyampaian dalam bentuk gambaran secara realistik. Menurut Wood (2007:68) bahwa beberapa karakteristik kesulitan siswa dalam belajar matematika : (1) kesulitan membedakan angka, simbol-simbol, serta bangun ruang, (2) tidak sanggup mengingat dalil-dalil matematika, (3) menulis angka tidak terbaca atau dalam ukuran kecil, (4) tidak memahami simbol-simbol matematika, (5) lemahnya kemampuan berpikir abstrak, (6) lemahnya kemampuan metakognisi dapat dikatakan lemahnya kemampuan mengidentifikasi serta memanfaatkan algoritma dalam memecahkan soal-soal matematika (dalam Untari, 2013:2). Dari enam point di atas bahwa pembelajaran matematika pada tingkat sekolah dasar belum dapat tercapai ke tingkat lebih tinggi saat mereka sudah menginjak ke sekolah menengah jika siswa belum mengerti dan memahami apa-apa tentang matematika dasar, artinya perlu prasyarat yang harus diketahui oleh siswa. padahal, kegunaan matematika untuk siswa banyak manfaatnya di dalam kehidupan sehari-hari, sesuai Bernard (2015:198) bahwa, Salah satu tujuan pembelajaran matematika adalah untuk melatih cara berpikir dan bernalar dalam menarik kesimpulan serta mampu mengungkapkan pendapatnya dengan rasa percaya diri dan kejujuran yang timbul dari seseorang untuk memecahkan masalah yang dihadapi. Melihat dari kondisi tersebut, diharapkan mahasiswa pendidikan matematika sebagai calon guru perlu memiliki strategi untuk mengatasi untuk meningkatkan kemampuan siswa dapat tercapai. Dan yang harus dilakukan mahasiswa saat ini adalah memiliki kekreatifannya untuk menciptakan suatu hasil karya berupa media pembelajaran matematika agar matematika mudah dipahami oleh siswa.

Beberapa yang harus dipertimbangkan mengenai media oleh para mahasiswa pendidikan matematika sebagai calon guru yaitu mampu memberikan gambaran yang jelas dari bentuk abstrak, hal ini sejalan menurut Sitanggang (2013: 4) yang mengemukakan fungsi utama mengenai media pembelajaran matematika dengan menggunakan alat peraga harus disesuaikan dengan tujuannya. Salah satu media pembelajaran matematika yang lebih efektif dan ekonomis adalah media yang berbantuan ICT, sedangkan kebanyakan kendala dari mahasiswa adalah penggunaan software matematika yang baru dan penggunaan animasi belum dapat dikuasai. Namun, Microsoft Excel merupakan software yang banyak ditemui oleh banyak orang saat menggunakan pengolahan data dan ada kaitannya tentang pemanfaatan fungsi matematika. 
Kaitan media pembelajaran matematika dengan Microsoft Excel, dibutuhkan adanya kemampuan kreatif mahasiswa dengan menciptakan berbagai cara, salah satunya ketercapaian mahasiswa membuat program matematika untuk memahami siswa di sekolah dasar mengenai tentang bilangan, operasi hitung dan geometri. Visual Basic for Excel merupakan bahasa program Microsoft Excel yang dapat dimanfaatkan fungsi-fungsi matematika yang mengatur obyek-obyek gambar yang disebut Shapes untuk lebih interaktif. Mahasiswa dapat memunculkan berbagai banyak ide gagasan yang tertuang dengan menggunakan pendekatan problem posing. Pendekatan ini berguna untuk mahasiswa akan diberi masalah yaitu tentang gambar yang disediakan dari Shape Microsoft Excel, dan langkah pertama, mahasiswa mengajukan pertanyaan dari gambaran atau shape tersebut yaitu akan dibuat apa yang kaitannya tentang alat peraga media matematika sebagai rencana pembuatan. Langkah kedua, mahasiswa akan mengajukan solusi pemecahan masalah untuk membuat permainan matematika, dan terakhir, mahasiswa akan mengajukan solusi setelah pemecahan masalah yaitu membuat rencana pembuatan alat peraga yang baru atau mengembangkan alat peraga (Silver \& Cai, 1996,292).

\section{METODE}

Penelitian ini, dilakukan menggunakan Kuasi eksperimen dilakukan 2 kelompok untuk menganalisis kemampuan kreatif mahasiswa pada mata kuliah Aplikasi TIK dalam pembelajaran Matematika Sekolah Dasar. Dimana 2 kelompok tersebut terdiri kelompok 1 yaitu kelas kontrol yang pembelajaran biasa menggunakan TIK sedang kelompok 2 adalah kelas eksperimen yang pembelajarannya dengan pendekatan problem posing menggunakan TIK, penilaian mahasiswa berdasarkan hasil karya mahasiswa dengan menggunakan cara biasa dan mahasiswa dengan menggunakan pendekatan problem posing dalam pembuatan alat peraga matematika sebagai media pembelajaran matematika sekolah dasar pada saat akhir pembelajaran.

\section{HASIL DAN PEMBAHASAN}

\section{Hasil}

Dari hasil yang diperoleh 33 mahasiswa diperoleh bahwa untuk mahasiswa yang memahami tentang operasi hitung seperti penjumlahan, pengurangan, pembagian dan perkalian ada $73,91 \%$ dan ada yang masih mengikuti contoh gambar tanpa membuat sendiri ada $60,86 \%$, penguasaan matematika yang lain seperti membuat geometri bidang, pecahan, akar, pangkat selain operasi hitung ada 17,39\% dan membuat kreasi aplikasi kalkulator yang dihubungkan dengan gambar yang interaktif ada 8,69 \%. Ini berarti menunjukan sebuah gambaran, bahwa pertama, pembuatan operasi hitung lebih mudah dipahami oleh mahasiswa tetapi ditemukan kesalahan mahasiswa kebanyakannya tidak memperhatikan mengenai operasi hitung bagi, jika ada nilai bilangan penyebut sama dengan nol. Kedua, banyak mahasiswa belum bisa mengembangkan hasil karya sendiri atau memunculkan gagasan-gagasan yang baru. Ketiga, kebanyakan mahasiswa belum bisa menghubungkan fungsi matematika ke dalam bentuk-bentuk gambar.

Hasil karya mahasiswa setelah pembelajaran ditemukan beberapa kemampuan Kreatif mahasiswa untuk penguasaan matematika dan temuan lain dari gagasan baru mahasiswa yaitu pada kelas yang pembelajaran matematika menggunakan Visual Basic Application for Excel melalui pendekatan problem posing, ada $40 \%$ mahasiswa sudah menguasai tentang operasi 
hitung, 45,7\% mahasiswa mampu menghubungkan aplikasikan bilangan dalam sel Microsoft Excel. 60\% mahasiswa mampu menggunakan shapes atau bentuk gambar untuk diberi perintah menjalankan hasil dari kode VBA for Excel. 20\% mahasiswa mampu membuat permainan di Microsoft Excel. 51,43\% mahasiswa mampu memberikan penjelasan pembuatan alat peraga menggunakan Microsoft Excel. 42,8\% mahasiswa mampu membuat alat peraga yang berkaitan dengan geometri. $28,57 \%$ mahasiswa mampu membuat alat peraga yang mengkaitkan dengan aritmatika. 31,43\% mahasiswa membuat alat peraga yang interaktif dengan hal-hal yang baru dan 20\% Mahasiswa mahasiswa membuat dengan alat peraga berbasis animasi.

Dapat kita peroleh data tersebut bahwa saat awal pengenalan Aplikasi TIK dalam pembelajaran Matematika Sekolah Dasar untuk pembuatan alat peraga 73,91\% mahasiswa lebih menyukai operasi hitung ternyata setelah mengetahui fungsi Microsoft Excel ada $40 \%$ menyukai operasi hitung tetapi mahasiswa sudah bisa menghubungkan $42,8 \%$ geometri seperti bangun ruang dan bidang datar dan $28,57 \%$ pengembangan konsep aritmatika seperti pecahan, pangkat dan akar. Dan ada peningkatan hasil kreatif mahasiswa buatan sendiri yang awalnya $8,69 \%$ dan $60,86 \%$ mahasiswa masih tergantung contoh gambar dan pembuatan VBA for Excel berarti 39,14\% masih bergantung contoh membuat VBA for Excel dan setelah pembelajaran 31,43\% mahasiswa membuat gagasan baru dan membuat hasil karya sendiri tanpa mengikuti contoh ditambahkan dengan 20\% mahasiswa yang membuatan animasi yang interaktif.

Tabel 1. Nilai Rata-rata dan Standar Deviasi dari Pendekatan Problem Posing Dan Pembelajaran Cara Biasa

\begin{tabular}{cccc}
\hline Pendekatan & N & Rata-Rata $(\bar{x})$ & Standar Deviasi (s) \\
\hline Problem Posing & 33 & 73,70 & 6,65 \\
Cara Biasa & 29 & 69,69 & 5,95 \\
\hline
\end{tabular}

Dari peroleh nilai rata-rata antara pendekatan Problem Posing dengan cara biasa adanya perbedaan, dimana rata-rata pendekatan problem posing lebih tinggi dibandingkan dengan pembelajaran cara biasa. Unruk melihat adanya perbedaan rata-rata kedua kelas akan diuji normalitas diperoleh nilai sig 0,133 untuk kelas eksperimen dan sig 0,125 untuk kelas kontrol, sehingga kedua data normal karena lebih dari 0,05 (nilai sig tabel) maka dilanjutkan dengan uji homogen dari kedua kelas dan diperoleh Uji F 0,81 dan nilai sig 0,372 lebih besar dari sig tabel 0,05 , artinya kedua tabel homogen, lalu dilanjutkan dengan uji $t$ untuk melihat perbedaan ratarata dan diperoleh perbedaan rata-rata 4,007 dan nilai sig 0,016 kurang dari sig tabel 0,05, artinya bahwa pembelajaran dengan menggunakan berpikir kreatif mahasiswa dengan pendekatan problem posing dengan Visual Basic for Excel lebih baik dengan cara biasa menggunakan Microsoft Excel tanpa menggunakan Visual Basic Application for Excel.

\section{Pembahasan}

Pada awalnya mahasiswa diberi pemahaman awal mengenai tentang Visual Basic Application for Excel, tujuannya adalah mahasiswa memiliki prasyarat untuk mengembangakan alat peraga yang sederhana. Mahasiswa mengenalkan terlebih dahulu tentang memunculkan bilangan bulat, seperti bilangan Asli, bilangan Genap, bilangan Ganjil, dan bilangan Prima (Bernard, 2016:169). Untuk tahap lebih sedikit meningkat mahasiswa diberikan pengetahuan dasar yaitutentang pembuatan kalkulator sederhana. Rencana pertama, siswa pertama menngajukan membuat pertanyaan, apakah bisa pembuatan kalkulator menggunakan tombol 
CommandButton yang daimbil dari DEVELOPER, Insert, lalu ActivexControl? Lalu siswa membuat hasil kerja.

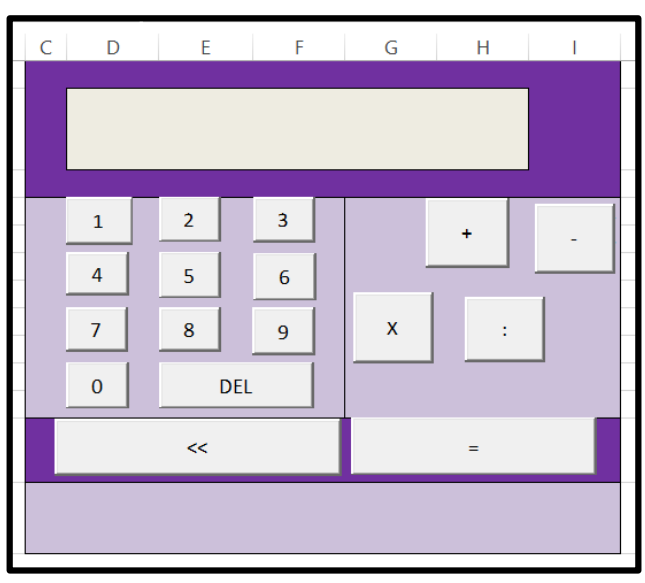

(a)

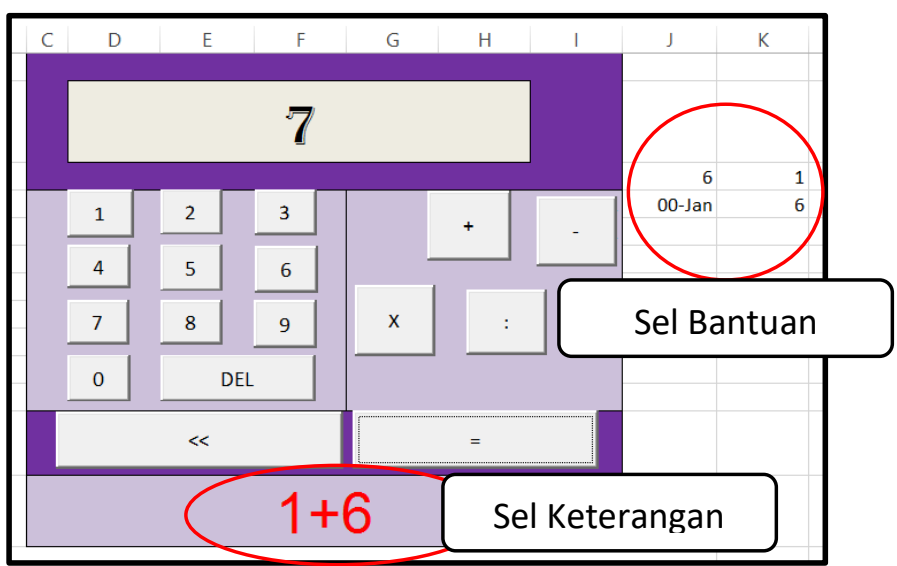

(b)

Gambar 1. (a) Membuat Kalkulator Menggunakan CommandButton.

(b) Menanpilkan hasil kalkulator

Mahasiswa membutuhkan bantuan sel J3 dan sel K5 dalam proses pembuatan kalkulator dengan menggunakan Visual Basic Application for Excel, alasannya mengatasi terjadi kesalahan pada operasi pengurangan. Saat memasukan angka 9 - 6, yang terjadi adalah "6 September", sehingga label pada kotak keterangan harus dihapus di format kembali menjadi general. Namun hasil utamanya tidak terjadi kesalahan. Adapun proses berpikir mahasiswa membuat kalkulator dari mahasiswa pertama sebagai berikut.

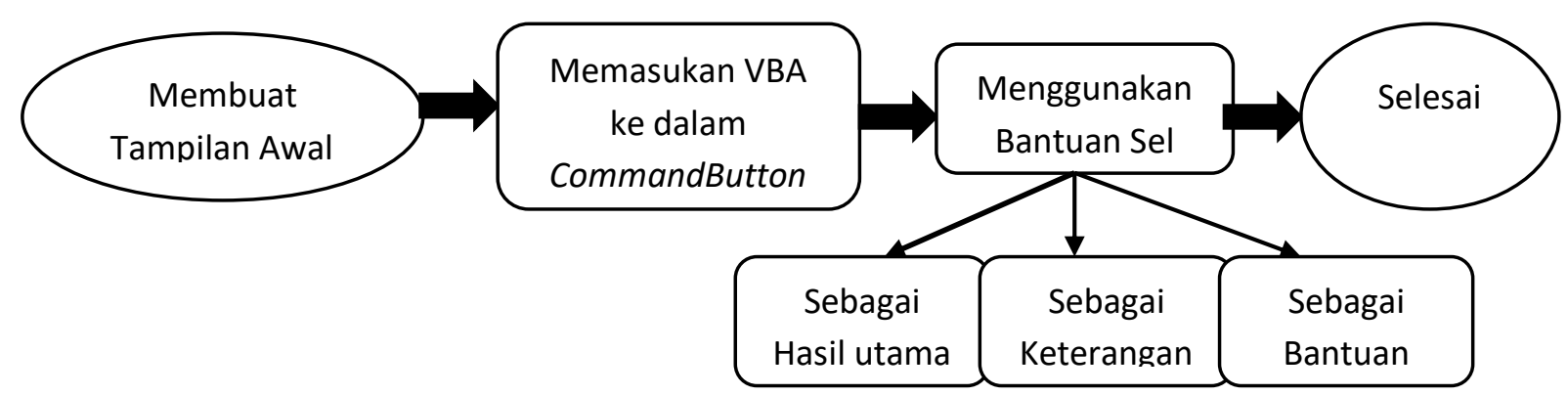

Gambar 2. Langkah-langkah Proses Berpikir Kreatif Mahasiswa Pertama

Mahasiswa yang kedua merencanakan untuk membuat kalkulator dengan menggunakan Shapes dari menu INSERT. Mahasiswa membuat pertanyaan bagaimana cara hubungan VBA for Excel dengan menggunakan Shapes atau gambar ke dalam Microsoft Excel untuk permainan Operasi Hitung? Lalu mahasiswa yang kedua membuat programnya.
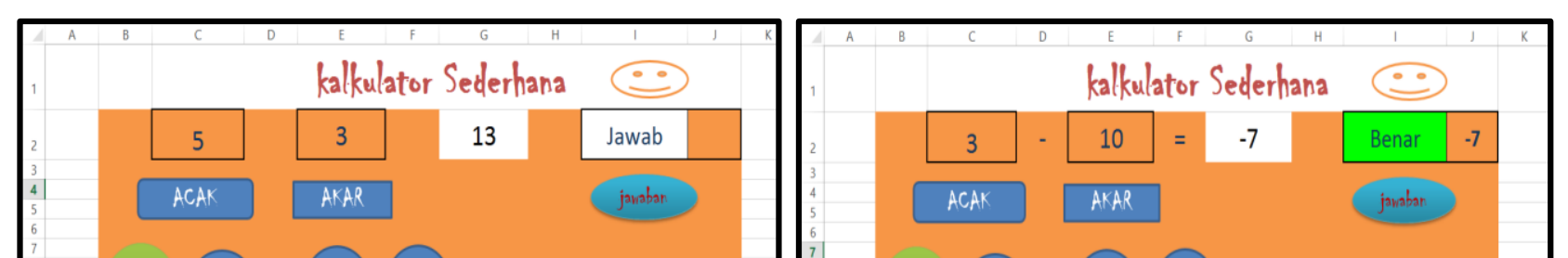
(a)

(b)

Gambar 3. (a) Membuat Kalkulator Menggunakan Shapes.

(b). Menanpilkan hasil kalkulator Mahasiswa yang Kedua

Kalkulator yang dibuat oleh mahasiswa yang kedua, berbeda cara dengan menghubungkan VBA for Excel melalui tool Macro tetapi tetap berada pada Menu DEVELOPER. Cara menghubungkan antara shapes dan VBA for Excel adalah dengan menggunakan Assign macro. Ada beberapa kelemahan pembuatan kalkulator yang dibuat oleh mahasiswa kedua adalah fungsi tombol acak belum memahami mengenai fungsi Randomize, akibatnya saat menekan tombol Acak, kembali ke angka awal berulang kembali. Kelemahan kedua, saat menekan acak sel jawaban tidak terhapus. Kelebihan dari kalkulator ini adanya interaksi siswa untuk menjawab benar dan salah. Proses berpikir mahasiswa kedua untuk membuat kalkulator sebagai berikut.

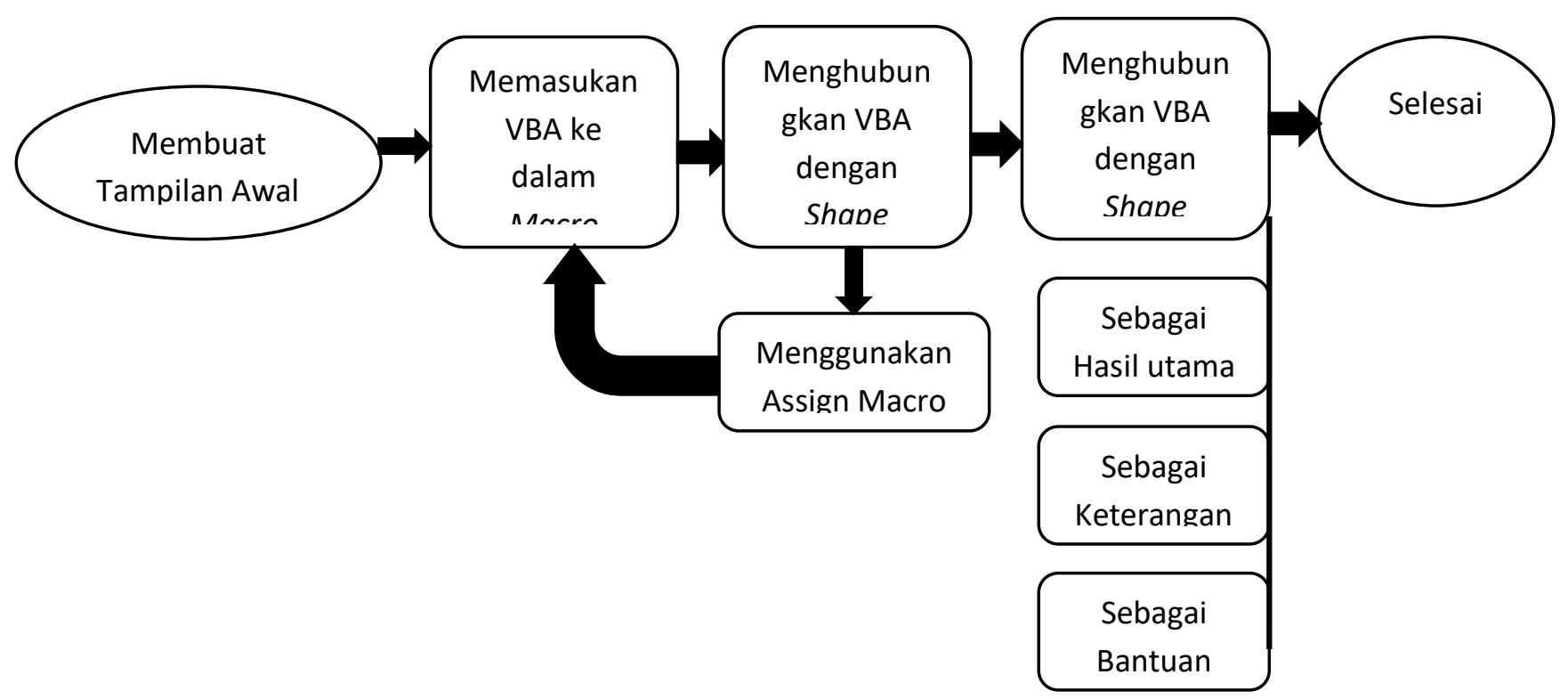

Gambar 4. Langkah-langkah Proses Berpikir Kreatif Mahasiswa Kedua

Temuan ketiga dari dari pertanyaan mahasiswa membuat kalkulator dengan menggunakan hubungan ukuran hasil perkalian dua bilangan bulat positif dengan gambar Shape sebagai bentuk luasannya. Dan pertanyaan dari mahasiswa ketiga adalah bagaimana hubungan hasil hitungan perkalian ditentukan dengan menggunakan gambar yang interaktif sesuai hasilnya. Lalu mahasiswa ketiga membuat rancangan gambaran yang dihubungkan dengan VBA for Excel. Dan hasil dari pengerjaan mahasiswa ketiga sebagai berikut. 


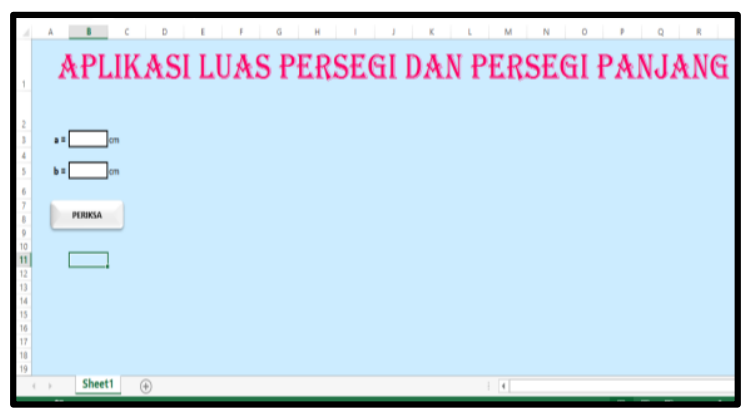

(a)

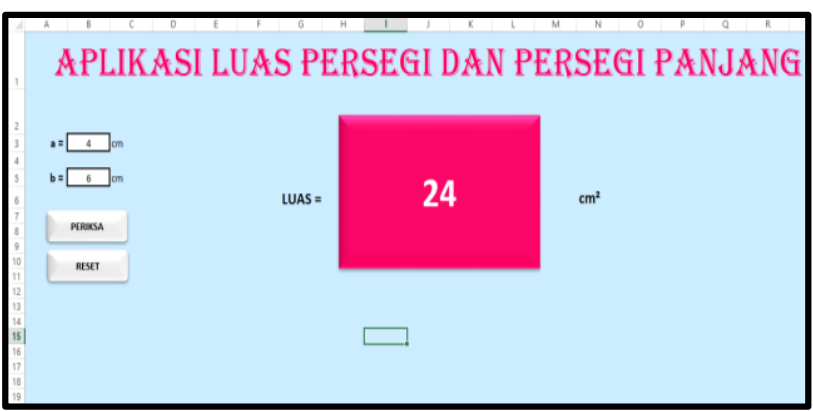

(b)

Gambar 5. (a) Membuat memerintah dan diperintah menggunakan Shapes

(b) Hasil Interaktif Shapes dengan VBA for Excel

Kalkulator mahasiswa ketiga, berusaha membuat tombol-tombol perintah untuk memberikan pada gambar yang diperintah oleh tombol-tombol tersebut, yaitu dengan cara memasukan nama terlebih dahulu pada shapes dengan menggunakan Selection Pane dari menu HOME dan select. Lalu memerintahkan menghubungkan nama tersebut dengan Visual Basic Application for Microsoft Excel. Kekurangan dari hasil kalkulator ini, tidak mengubah ukuran gambar atau shape yang diperintah jika saat memasukan ke dalam berbagai nilai pada sel input. Kelebihan dari hasil kalkulator tersebut adalah menampilkan hasil di dalam gambar atau shapes, dengan cara memunculkan dan menyembunyikan gambar. Proses berpikir dari mahasiswa kreatif dari mahasiswa ketiga sebagai berikut.

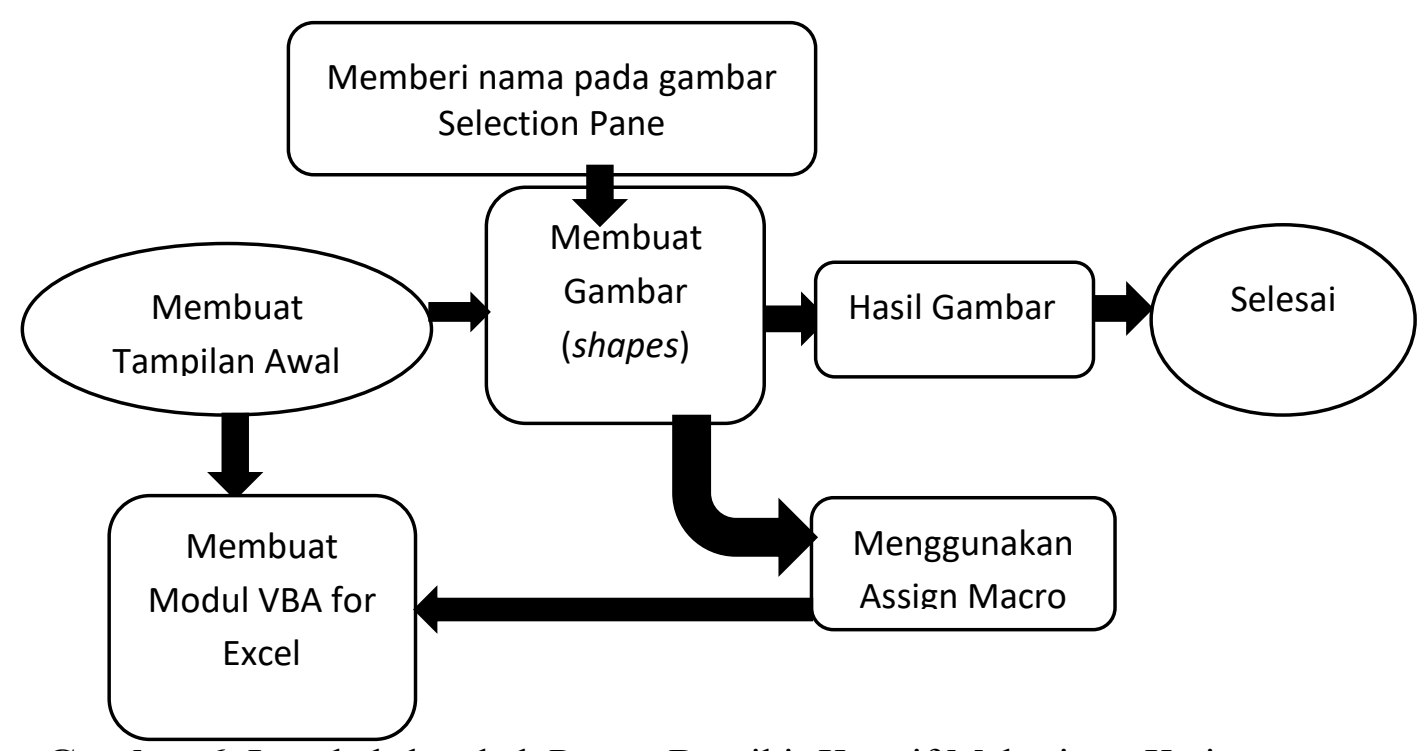

Gambar 6. Langkah-langkah Proses Berpikir Kreatif Mahasiswa Ketiga

Dari analisis dari 35 mahasiswa, ada beberapa cara bagaimana mahasiswa mampu membuat hasil penerapan matematika ke dalam Microsoft Excel dengan bantuan Visual Basic for Excel agar matematika tersebut menjadi alat peraga yang dapat disampaikan kepada siswa-siswa sekolah dasar yaitu, Pertama, Mahasiswa sudah memahami operasi hitung merupakan suatu pengetahuan dasar untuk mengenal tentang bahasa program VBA for Excel, berarti memberikan beberapa fungsi-fungsi matematika lain yang disesuaikan dengan kemampuan pembuatan proses algoritma mahasiswa. Kedua, cara menghubungkan antara bahasa VBA for Excel dengan gambar yang lebih interaktif. Ketiga, memberikan contoh hasil karya yang menarik agar mahasiswa dapat termotivasi untuk memunculkan ide-ide kreatif membuat alat 
peraga yang lain. Keempat, pemanfaatan Microsot Excel dalam pembuatan alat peraga di sekolah dasar.

Dari hasil pengamatan diatas, akan dicobakan kepada 2 kelas yaitu kelas kontrol yaitu pembelajaran aplikasi Matematika dengan Microsoft Excel yang menggunakan cara biasa dan kelas eksperimen yaitu pembelajaran aplikasi matematika dengan menggunakan pendekatan problem posing. Dan beberapa yang dihasilkan setelah melakukan empat cara oleh para mahsiswa sebagai berikut.

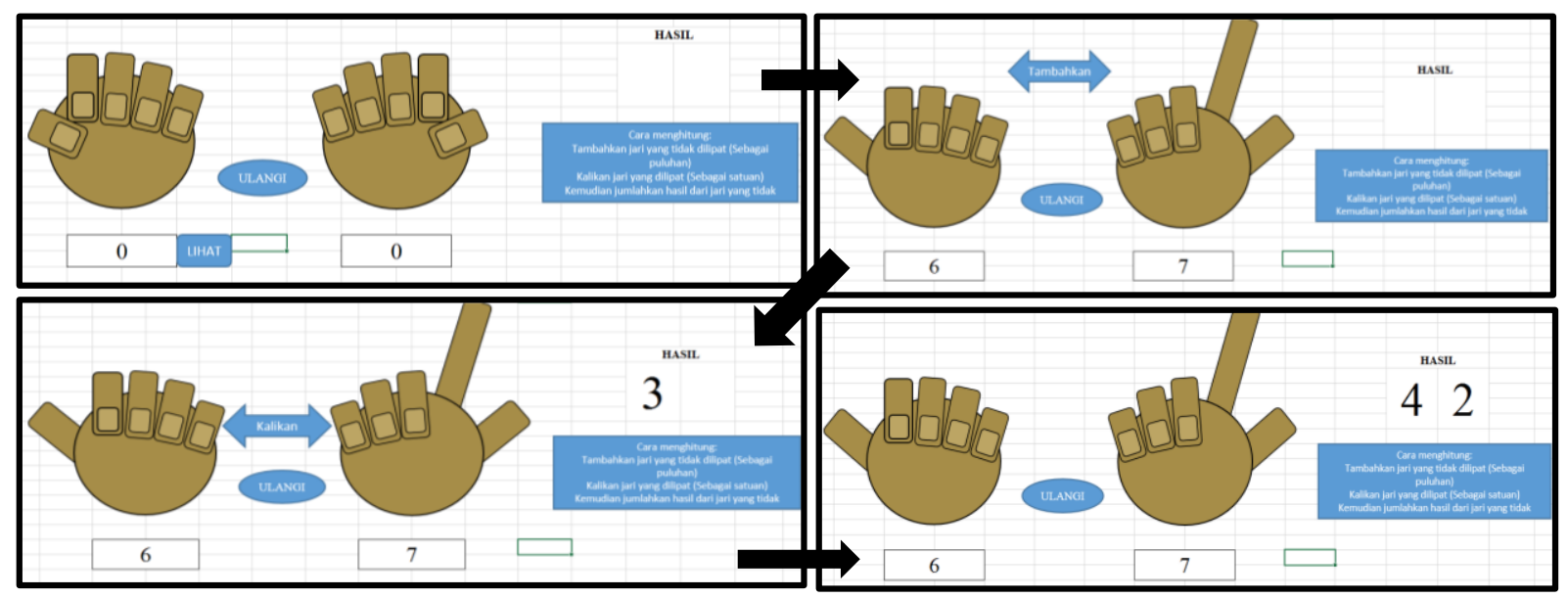

Gambar 7. Hasil Kreatif Mahasiswa membuat alat Peraga Jarimatika

Pembuatan alat peraga jarimatika dibuat oleh salah satu mahasiswa yang bernama Angga Andriawan, dia mencoba konsep perkalian menggunakan jari-jari dari kedua tangan kepada siswa kelas dua sekolah dasar dimana pemanfaatan gambar di dalam Microsoft Excel sebagai alat peraga untuk penguasaan perkalian.

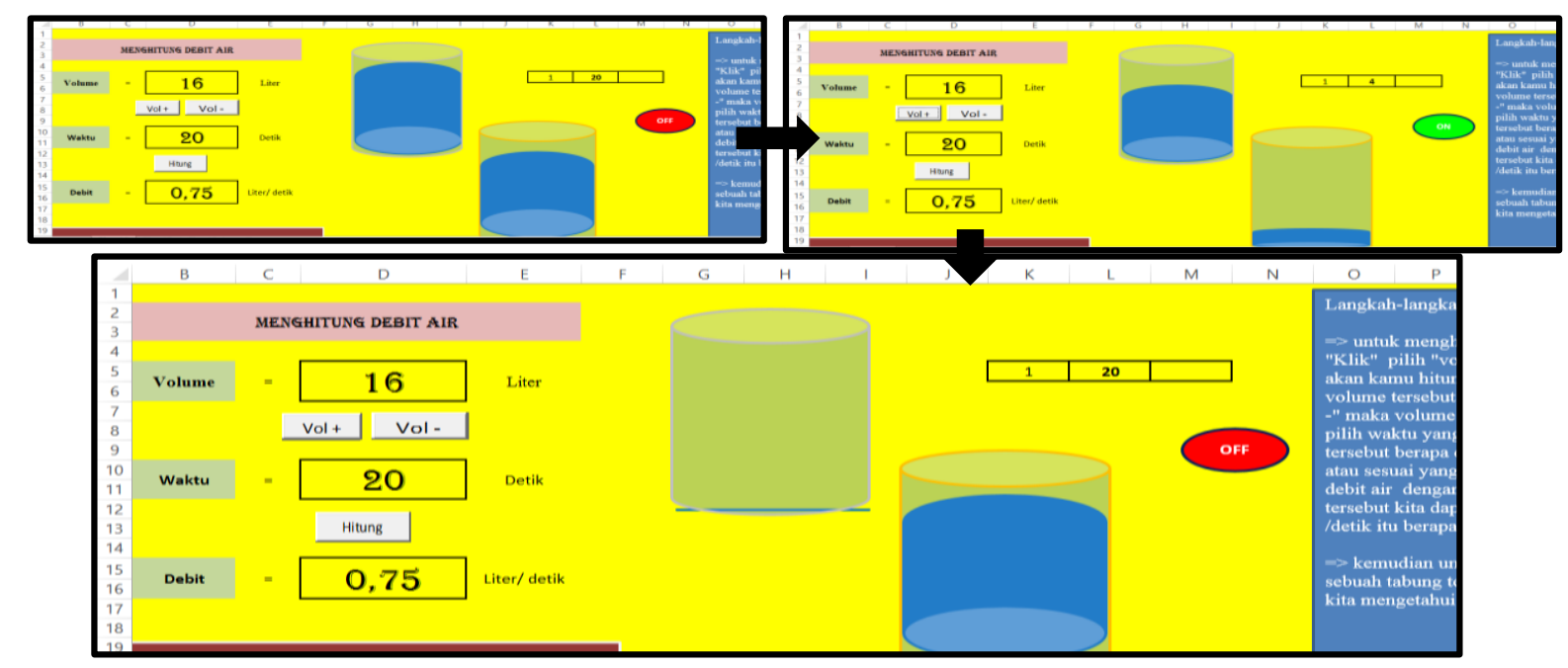

Gambar 8. Hasil Kreatif Mahasiswa Membuat Alat Peraga Debit Air

Mahasiswa yang membuat alat peraga Debit Air yang dibuat oleh Elsa Fitri, dimana media pembelajaran tersebut memberikan pemahaman kepada anak kelas 6 sekolah dasar. Tujuannya adalah agar sisw sekolah dasar kelas 6 memahami kelajuan volume air dalam satuan waktu dan penggunaan Microsoft Excel menggunakan fungsi waktu agar melihat bergeraknya air dari wadah pertama ke wadah kedua dalam waktu yang ditentukan saat siswa menyeting waktu dan volume, perjalanan pemindahan air tersebut berdasarkan hasil dari debit. 

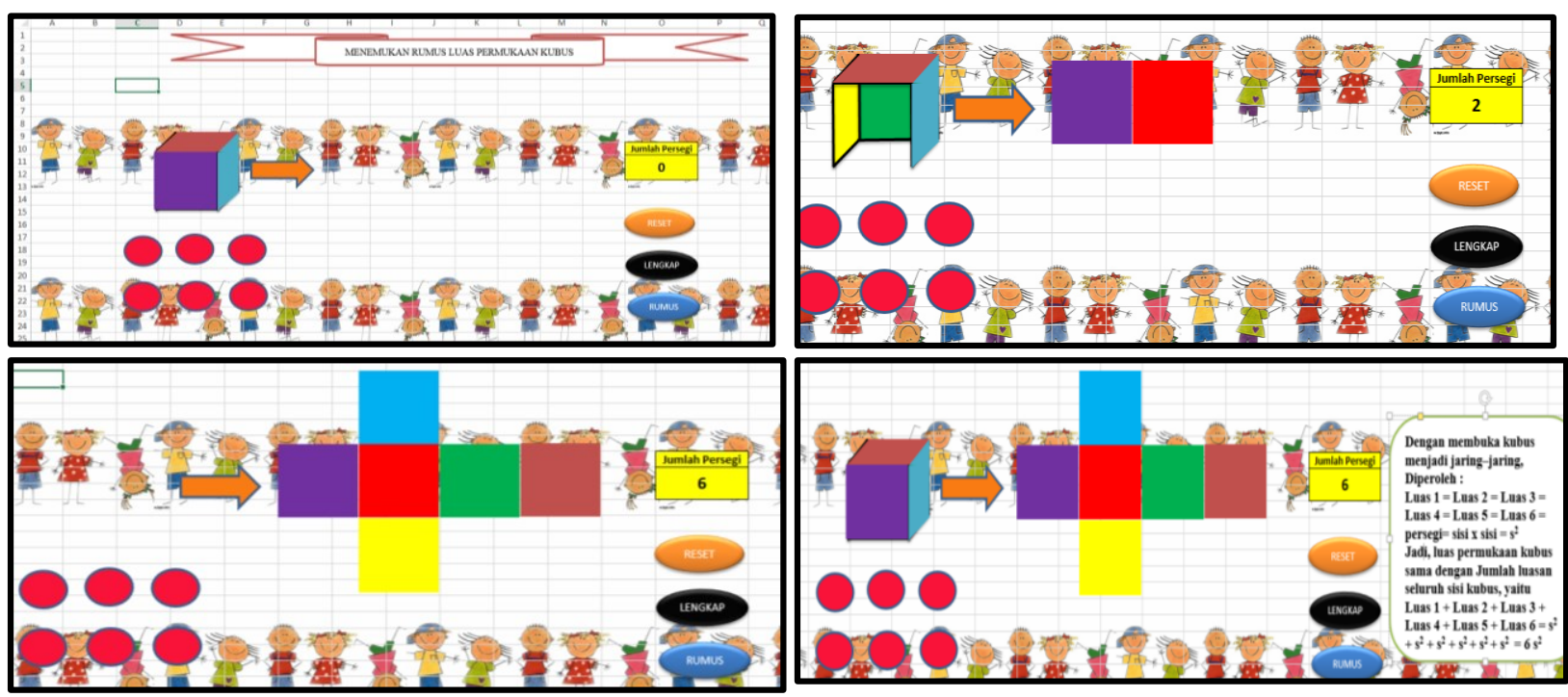

Gambar 9. Hasil Kreatif Mahasiswa Membuat Alat Peraga Menemukan Jumlah Sisi Kubus

Hasil kreatif mahasiswa adalah membuat alat peraga untuk menemukan sisi kubus dan luas sisi kubus untuk kelas 4 sekolah dasar dari Febrianingsih Timutius, alat peraga tersebut agar siswa kelas 4 sekolah dasar mudah memahami bagaimana mencari tentang luas dari bentuk fisik sisi kubus yang dipecah-pecahkan sambil menyusun bentuk sisi luasannya.

\section{KESIMPULAN}

Jadi untuk Kemampuan Kreatif Mahasiswa Matematik melalui Pendekatan Problem Posing dengan berbantuan Visual Basic Application for Excel lebih baik dibandingkan dengan cara biasa dengan berbantuan Visual Basic Application for Excel, dan adanya peningkatan kemampuan kreatif matematika sekolah dasar saat sebelum menggunakan Visual Basic Application for Excel dengan sebelum menggunakan

\section{DAFTAR PUSTAKA}

Untari, E. (2014). Diagnosis Kesulitan Belajar Pokok Bahasan Pecahan pada Siswa Kelas V Sekolah Dasar. Jurnal Ilmiah STKIP PGRI Ngawi, 13(1), 1-8.

Bernard, M. (2015). Meningkatkan kemampuan komunikasi dan penalaran serta disposisi matematika SMK dengan pendekatan kontekstual melalui game adobe flash cs 4.0. Infinity Journal, 4(2), 197-222.

Bernard, M. (2016). Pengaruh Visual Basic Application For Excel Terhadap Kemampuan Kreatif Mahasiswa tentang Definisi dan Teorema Matematika. Prosiding Seminar Nasional Matematika dan Pendidikan Matematika STKIP Siliwangi Bandung, Volume 4, hal. $167-175$

Sitanggang, A. (2013). Alat Peraga Matematika Sederhana Untuk Sekolah Dasar. Medan: Lembaga Penjaminan Mutu Pendidikan Sumatera Utara. 
Silver, Edward A and Cai, Jinfa (1996)."An Analysis of Arithmetic Problem Posing By Middle School Students". Journal For Research In Mathematics Education, Volume 27. No. 5, p. 521-539 